\title{
A study of the early signs of drug induced Parkinsonism
}

\author{
L A Arblaster, M Lakie, W J Mutch, M Semple
}

\begin{abstract}
Postural tremor was recorded from psychiatric patients who had been treated with phenothiazine or butyrophenone neuroleptic drugs. None of the patients had previously been diagnosed as having extrapyramidal dysfunction. A significant number of these patients had abnormally low tremor frequencies. Low frequency tremors are often associated with Parkinson's disease (PD) so that some of these patients may have early signs of drug induced Parkinsonism (DIP). The results indicate that DIP is not necessarily characterised by a bilateral slow frequency tremor, but may initially be similar to idiopathic PD, even though its cause and prognosis are different.
\end{abstract}

(F Neurol Neurosurg Psychiatry 1993;56:301-303)

One symptom of idiopathic PD is often slow frequency resting and postural tremor (4-6 $\mathrm{Hz}) .{ }^{1}$ In healthy subjects the size of tremor may vary greatly. According to one study ${ }^{2}$ postural tremor size has a 23 fold range, and a more recent study has shown that the range may be as much as $100 .^{3}$ This variation implies that there is a considerable overlap between the tremor size of some apparently healthy people and patients with neurological disorders. In the general population there will be some people with a large tremor which may, or may not, be an indication of neurological disease.

The peak frequency of tremor is a much more stable parameter. In normal subjects frequencies of less than $7 \mathrm{~Hz}$, and more than $11 \mathrm{~Hz}$ are rare. ${ }^{3}$ Unlike size, the frequency of tremor is not obvious on visual examination. Tremor is normally only brought to the attention of clinicians when its size become noticeable. It is therefore of interest if low frequency, normal amplitude tremors can be detected because this may be the first sign of a developing neurological disorder. Such tremors can only be detected instrumentally.

Some drugs used in psychiatric disorders are well known to induce Parkinsonism. The symptoms may be indistinguishable from the idiopathic form of the disease, but it has been reported that tremor is not commonly seen. ${ }^{4}$ The aim of this study was to determine whether a lowering of postural tremor fre- quency could be instrumentally detected in a group of patients who had received drugs of this type. An abnormally low frequency tremor might be regarded as an early sign of drug induced Parkinsonism (DIP).

This study was not designed as a clinical investigation of the side effects of a specific type or dose of drug. The intention was to screen a large group of patients who had all been treated with one category of drug to determine whether a significant number had developed abnormal tremor, compared with an age-matched control group who had not been exposed to drugs of this type.

\section{Methods}

Forty nine patients were investigated, twenty three were male. The age range was 18 to 69 (mean 54.3) years. Patients were chosen who had been treated with neuroleptic drugs of the phenothiazine or butyrophenone types for at least one month in the previous year. As is typically the case, a wide range of types and doses of psychoactive drugs, had also been administered to these patients. These patients were compared with a large, age and sex matched control group of apparently healthy subjects (154) taken from the general population. Informed consent from the subjects was obtained and the study was approved by the hospital ethical committee.

Postural wrist tremor was recorded simultaneously and bilaterally by solid state accelerometers (ICS 3021) which were attached to the tip of the middle finger of each hand. ${ }^{5}$ The subject sat in a comfortable chair with the elbow flexed at approximately $90^{\circ}$. The pronated forearms were held in a cradle of "Velcro" straps. The cradle terminated at the wrist joint so that the hand and fingers were unsupported-the subject was asked to use minimal force to hold the hands approximately horizontal with the fingers slightly abducted. Following amplification and low pass filtering, data were sampled at $100 \mathrm{~Hz}$ and stored on disc. A record lasted 80 seconds. Fourier analysis was performed to extract two parameters: 1) The peak frequency of the tremor and 2) The size of the tremor (acceleration) at the peak frequency. To ensure that the frequency spectrum was representative of the whole epoch, the record was divided into 30 overlapping slices (10 seconds) which were individually analysed. The average of these thirty slices was used for the subsequent analysis. 

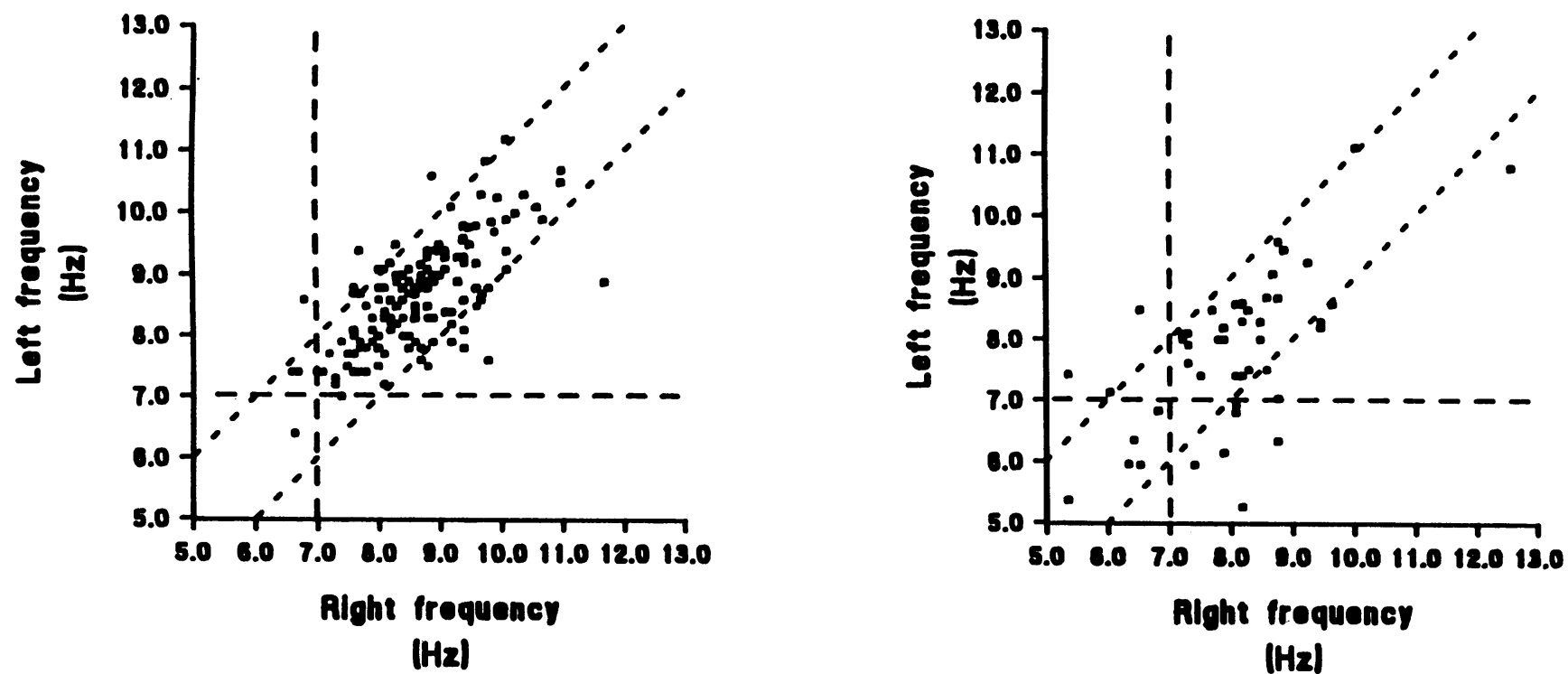

Fig $1 A$ (Left) Frequencies of the tremor peak for left and right wrists in 154 normal subjects aged 18-69. Usually left and right frequencies are quite well matched (within $1 \mathrm{~Hz}$ ). Few subjects have a tremor that is less than $7 \mathrm{~Hz} .1 \mathrm{~B}$. (Right) Frequencies of the tremor peak from the 49 psychiatric patients. Fourteen people have a frequency less than $7 \mathrm{~Hz}$. In several of these there is a large disparity in frequency between left and right sides.

\section{Results}

Tremor size

In the 154 normal subjects, the peak acceleration of wrist tremor ranged from $1-100 \mathrm{~cm}$ $\mathrm{s}^{-2}$. The data recorded from the psychiatric patients showed the same range of sizes. Thus the patients and normal subjects could not be distinguished on the basis of tremor size.

\section{Tremor frequencies}

In the 154 normal subjects, 5 had a tremor frequency of $7 \mathrm{~Hz}$ or less (3.2\%) (fig). Nearly all the subjects had a tremor frequency which was well matched on left and right sides, 93\% had a left/right difference of $1.4 \mathrm{~Hz}$ or less.

In the 49 psychiatric patients 14 (8 female, 6 male) had tremors less than $7 \mathrm{~Hz}(29 \%)$. Five subjects showed a peak frequency of less than $7 \mathrm{~Hz}$ bilaterally and nine showed a unilateral low frequency tremor. Following tremor measurement, patients showing a tremor frequency of less than $7 \mathrm{~Hz}$, either uni- or bilaterally were referred for clinical examination. It was possible to examine only 10 of these 14 patients. Seven of this group showed Parkinsonian signs of bradykinesia, rigidity, lack of facial expression and disturbed posture. As previously reported, these signs are indistinguishable from those in idiopathic PD. ${ }^{6}$

\section{Discussion}

In this study $28 \%$ of the psychiatric patients had low tremor frequencies which merited further investigation. This is somewhat higher than the proportion reported by other groups. ${ }^{4}$ It lends support to $\mathrm{McClelland}^{7}$ who stated that the problem was much underreported and prevalence rates of $60 \%$ were more likely. The age range in this study was deliberately limited at 69 in an attempt to try to reduce the number of patients who may be predisposed to idiopathic PD due to agerelated changes in the basal ganglia.

The development of DIP is usually thought to be bilateral. ${ }^{8}$ In this study, there was no single characteristic pattern of postural tremor. Five patients from a total of fourteen had a bilateral low frequency tremor and nine showed a low frequency tremor that was markedly unilateral. These results do not support the view that DIP is necessarily characterised by a bilateral tremor. As only a very small number of patients show any visible tremor, sensitive measurement is required to identify those patients who have abnormally low frequency tremors.

In this study it was not possible to link the development of low frequency tremor with a particular drug as a large range of medications had been used.

In the control group, which was a large, apparently healthy population a small number of individuals showed tremor frequencies that were slightly abnormal. This may be the first subclinical manifestation of disease. We do not know whether any of the control subjects involved in this group were taking or had even taken medication which may predispose to tremor, or suppress it. However, such drugs change the size of the tremor, not the frequency. Postural tremor frequency may also slow with age..$^{910}$

In conclusion, a sensitive tremor recording device can be a useful aid in the earlier detection and diagnosis of DIP.

1 Elble RJ and Koller WC. Tremor. Baltimore and London Johns Hopkins University Press: 1990, 135-6.

2 Wade P, Gresty MA, Findley LJ. A normative study of postural tremor of the hand. Arch Neurol 1982;39. 358-62.

3 Arblaster LA, Lakie M, Walsh EG. Human physiological tremor: a bilateral study. $\mathcal{F}$ Physiol 1990;429:132.

4 Ayd FJ. A survey of drug induced extrapyramidal reactions. FAMA 1961;175:1054-61.

5 Arblaster LA, Lakie M. Simultaneous bilateral recording of human tremor. $\mathcal{F}$ Physiol 1990:420:6. 
6 Marsden CD, Tarsy D, Baldessarini RJ. Spontaneous and drug induced movement disorders. In: Benson DR, Blainer D, eds. Psychiatric aspects of neurology disease Orlando, Florida: Grune and Stratton: 1975; 219-65.

$7 \mathrm{McClelland}$ HA. Discussion on assessment of drug induced extrapyramidal reactions. Br $¥ \mathrm{Clin}$ Pharmacol 1976:3(Suppl): 401-3.

8 Baldessarini RJ. Drugs and the treatment of psychiatric disorders. In: Gilman AG, Goodman LS, Rall TW,
Murad F, eds. The pharmacological basis of therapeutics, 7th ed. New York: Macmillan, 1985:387-445.

9 Birmingham AT, Wharrad HJ, Williams EJ. The variation of finger tremor with age in man. $\mathcal{F}$ Neurol Neurosurg of finger tremor with age in man. $f$ Neurol Neurosurg
Psychiatry 1985;48:788-98.

10 Kelly JF, Taggart HM, McCullagh P. Physiological tremor in an elderly population. In: Bartko D Gerstenbrand F, Turcani P, eds. Neurology in Europe 1 London, John Libby, 1989:541-5. 